\title{
On the Periodical Liberation of the Oospheres in Sargassum.
}

\author{
(Preliminary Note.)
}

By

\section{Tahara.}

In $1905 \mathrm{~J}$. LLOYD Williams published an interesting paper ${ }^{11}$ on the periodical development of the sexual cells of Dictyota dichotoma, growing on the coast of North Wales and Plymouth, England. According to him, the oospheres and spermatozoids of this alga are produced during its fruiting season in fortnightly crops, bearing a definit relation to the tides. In the next year this phenomenon in Dictyota was reexamined by W. D. HoyT $^{2)}$ at Beaufort, North Carolina. His observation however differed remarkably from that of Williams; the crops were borne at monthly instead of fortuightly intervals.

In the winter of 1908-1909 I had an opportunity to spend a few weeks at the Misaki Marine Biological Station of the Tokyo Imperial University. To my surprise it happened to me to find that Sargassum, one of the most common algae of Japan, presents also a similiar periodicity in the liberation of the oospheres. Along the coast of Misaki there are about ten species of Sargassum ${ }^{3}$, of which Sargassum enerve AG. was the one with which I have chiefly concerned. This species is very common in the vicinity and forms often a considerable mass. Its fruiting season begins at the beginning of December and continues probably till the end of April.

On the 16 th. of December, the next day of my arrival at Misaki, I met with some female individuals of this alga, that

1) Widrians, J. Lroynd. Studies in the Dictyotaceae. Annals of Potany. 1905.

2) Hort, W. D. Periodicity in the production of the sexual cells of Dictyota dichotoma. Botanical Gazette. 1907. Vol. XLIII.

3) Yexio, K. The Fucaceae of Japan. Journal of College of Science, Imperial University of Tokyo. Vol. XXI, Article 12. 
bore many sporelings in their reproductive branches. It may be remarked here in passing that the eggs of Sargassum, as already known, on leaving the conceptacle become fastened to the receptacle by mucilagenous substance, and before the departure from the parent stock which will take place after a few days, the segmentation proceeds to some extent.

At first sight I roticed that the sporelings attached were not distributed through the whole length of receptacle, but were confined to the lower or middle portion of it; in the latter case the lower portion of the receptacle was entirely free from oospheres. One might consider as follows : the liberation of oospheres would have begun at the very base of receptacle and proceeded gradually towards the apex. But the closer examination of sporelings proved that it was not the case, because the segmentation of the sporelings in one receptacle was nearly in the same stage, that is the sporelings near the base were not segmented any farther than those towards the apex. This facts reminded me of the periodical liberation of the sexual elements in Dictyota dichotoma and induced me to devote myself to the farther investigation.

Before long, on the $24 \mathrm{th}$. of December, the next day after full moon, I was lucky to observe that almost all individuals of this alga on the coast discharged their oospheres simultaneously. The discharged oospheres stayed on the receptacle till 27 th. and dropped off also simultaneously, and on the 28th. there was no more a single stock that bore the sporelings in the receptacle. After a fortnight, on the 6th. of January, the day of new moon, the next general liberation of oospheres occurred in such a vivid way as before. The receptacles which discharged their oospheres on the 24th., repeated the same thing this time. Of course there were also many receptacles whose oospheres were liberated for the first time.

As I had to leave the station on the next day I cannot report how the plant went on thereafter. Althongh the above description is concerned to only one species, Sargassum enerve, I am convinced that the similar phenomenon will be common to all members of the genus; actually I observed on the 26 th. 
of December Sargassum Horneri AG. liberated many millions of oospheres simultaneously which disappeared on the 1st. of January. The receptacle of this species, favourable for obser-

Fig. 1. Fig. 2.

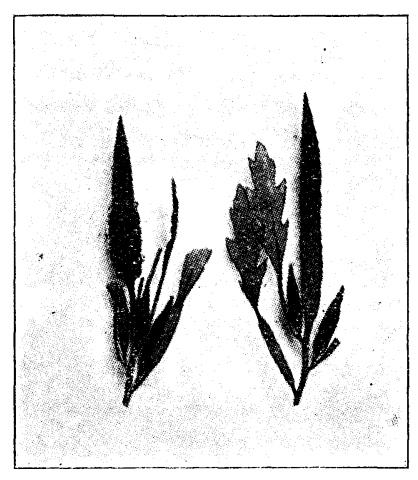
vation, is bigger than that of the former. The text figure 1 shows the female receptacle of this plant of $26 \mathrm{th}$. December. The black spots on its lower portion represent the discharged oospheres which were cleared off on the 1st. of January. (Fig. 2).

It seems to me that the oospheres of Fucus are not produced with periodicity because the oospheres of this genus, as it is well known, can be liberated from conceptacle at any time by several artificial processes. As far as I experienced, Sargassum behaves very differently, and I tried several times to apply similar processes in vain.

\section{SUMMARY.}

1. Liberation of oospheres in Sargassum takes place simultaneously, not only for a given plant but also for the all plants of the locality.

2. This simultaneous liberation proceeds in fortnightly crops on a particular day with a fixed interval after the highest spring tide; interval varies, however, in different species.

3 . The oospheres in one and the same receptacle are not discharged at one time but in two or three successive fortnightly crops. 